\title{
ANALYSIS OF RUSSIAN EDUCATION SYSTEM SELF-MOTION
}

\author{
Valery Smirnov ${ }^{1 \star}$, Vladislav Semenov ${ }^{2}$, Anna Zakharova ${ }^{3}$, Nina Gubanova ${ }^{4}$, Galina \\ Dulina $^{5}$ \\ ${ }^{1}$ Dr, Chuvash State University, Russia, walera712006@mail.ru \\ ${ }^{2} \mathrm{Dr}$, Chuvash State University, Russia, \\ ${ }^{3}$ Dr., Chuvash State University, Russia, \\ ${ }^{4} \mathrm{Dr}$, Chuvash State University, Russia \\ ${ }^{5}$ Dr, Chuvash State University, Russia \\ ${ }^{*}$ Corresponding Author
}

\begin{abstract}
The research into the self-motion of the Russian education system appears to be urgent due to its increasing role in the new world technological structure that is taking shape. Education system is a part of the social and economic structure and it specifies its contents through the complex of social institutes fulfilling organized and purposeful training of the rising generation for independent life in the contemporary society. Increasing role of the education system to form a new world technological structure as a part of social and economic structure of states points out to its strategic position within the system of national security.

Increasing role of the Russian education system in the new world technological structure being shaped stipulated the necessity to analyze significance of indicators covering the education cycle from preschool education to vocational and higher education, as well as describing access to education, stages of training, literacy, teachers, societies and expenses; to specify priorities of its development.

The subject matter of the research into self-motion of the Russian education system is attributed to the necessity of a spontaneous system change defined by its contradictions mediating the impact of external factors and conditions.

The article singles out roots that cause problems of education system formation and development.

The analysis of the Russian education system was conducted applying the data of the World Bank describing the access to the education, stages of study, literacy, teachers, societies, and expenses and those of the UNESCO Institute for Statistics applying its data base to support the policies and investments required for the life transformation and movement of the world towards its goals in the development of education, science, culture and communication. The methods of statistical, neural network and cluster analysis were applied in this research.

Neural network analysis growth rate of the Russian educational system resulted in hierarchy of significant indicators resembling the structure of the Russian educational system, feminization of the Russian educational system being marked out among these indicators. Inclination of internal motion of the Russian education system towards feminization is attributed to the early formation of the female cluster. Cluster analysis into the growth rate of the Russian education system self-motion clarified the reason for feminization. Analysis of the growth rate of the Russian education system self-motion applying the data of the UNESCO Institute for Statistics accomplished the picture of the prospects for the Russian education development. There were exposed negative indicators of the Russian education system self-motion as a considerable decrease in the share of preschoolers and younger preschoolers, a significant lag in the growth rate of public spending on education (\% of GDP) compared to the spending on education as a percentage of the total government spending.
\end{abstract}


The research resulted in the conclusion on feminization of the Russian education system self-motion, to a certain extent changing the principles of the society formation increasing the uncertainty of the prospects for its existence.

Keywords: uncertainty, education system, self-motion, society, feminization

\section{INTRODUCTION}

The research into the self-motion of the Russian education system appears to be urgent due to its increasing role in the new world technological structure that is taking shape. Education system is a part of the social and economic structure and it specifies its contents through the complex of social institutes fulfilling organized and purposeful training of the rising generation for independent life in the contemporary society (Smirnov, Semenov, Zakharova, Kadyshev and Dulina, 2019).

Education is defined as the process and the result of perfecting the abilities and behavior of an individual when he reaches social maturity and personal growth (UNESCO. United Nations Educational, Scientific and Cultural Organization); a purposeful process of upbringing and education which is of a social significant benefit and is carried out in the interests of a person, family, society and state, as well as an aggregate of knowledge, abilities, skills, value attitudes, experience and competence of certain capacity and complexity aiming at intellectual, spiritual, creative, physical and/or professional development of a person meeting his educational requirements and interests. Education results in a developed personality capable of selfdetermination and socialization based on the social and cultural and spiritual and moral values, rules and codes of ethics adopted in the Russian society pursuing the interests of a person, a family, society and state. this personality is characterized by patriotic sentiment, public spirit, respect for the defendants of the Fatherland and their heroic deeds, law and order, man of labor and older generation, mutual respect and respect for the cultural heritage and traditions of the multinational people of the Russian Federation, respect to the nature and environment (Federal Law of December 12.2012 N 273-\$3 as amended on July31, 2020 on Education in the Russian Federation, effective since September 1, 2020 with amendments).

Consequently, education results in shaping a personality possessing an aggregate of qualities which present categories of human capital. The basic conditions of providing education are as follows: education system comprising government educational standards and national requirements of different levels and directivity, establishments executing educational activities, teachers and educators, learners and their parents (legal representatives) of underage learners, organizations providing and monitoring educational activities, etc.

Different levels of education system control are distinguished: state control, municipal control and educational establishment control. These different control levels ensure a certain integrity of the education system institutionally conforming ties between their subsystems.

Increasing role of the Russian education system in the new world technological structure being shaped stipulated the necessity:(1) to analyze significance of indicators covering the education cycle from preschool education to vocational and higher education, as well as describing access to education, stages of training, literacy, teachers, societies and expenses; (2) to specify priorities of its development.

The subject matter of the research into self-motion of the Russian education system is attributed to the necessity of spontaneous system change defined by its contradictions mediating the impact of external factors and conditions (Smirnov, Talanova, Zakharova, Dulina, Getskina and Huraskina, 2018). At that change is a motion in general - the way of being of matter, its most significant attribute in its broadest sense, in simple terms - any interaction of material objects. Analysis of the Russian education system self-motion is supposed to reveal both structural contradictions and opportunities for its development.

\section{METHODOLOGY}

To find out financial and economic essence of the modern Russian capitalism we apply the methods of statistical, neural network and cluster analysis that include processing of statistical data, their systematisation and presenting them in the form of graphs and tables (King and Eckersley, 2019), (Brownstein, Adolfsson and Ackerman, 2019). Statistical data processing is carried out applying «IBM SPSS Statistics Software» (Fávero and Belfiore, 2019), and tabulation, diagrams and graph plotting - applying «MS Excel».

Statistical analysis is a method of collection, study and submission of big amounts of data on features 
(Lazar, Feng and Hochheiser, 2017) and interactions of data, correlations of spatial and time series of indices keeping the research methodology.

Neural network analysis allows you to identify changes in objects or phenomena through neural network forming. Application of the neural network analysis allows you to specify the significance of the indicators covering the cycle of education beginning from preschool education and ending with vocational and higher education, as well as describing the access to education, stages of training, literacy, teachers, society and expenses..

The application of cluster analysis is stipulated by the addition of probailictic understanding of casuality (Urlacher, 2020) with the connectivity of changes in the indicators being assessed. Cluster analysis allows you to accomplish collection of data containing the information on selection of objects and to arrange objects of research into relatively homogeneous groups (Adolfsson, Ackerman and Brownstein, 2019). It allows working out classification of objects and phenomena under analysis, finding out basic schemes of their clustering and formulating hypothesis (Favero and Belfiore, 2019). Cluster analysis reflects the priorities of the Russian education system.

Hypotheses obtained due to neural network and cluster analysis allow forecasting results of management decision-making that is being tested and being applied.

\section{LITERATURE REVIEW}

To analyze self-motion of the Russian education system it is necessary to singe it out of the material world and to define the problem of its existence under the conditions of objective reality. Matter is understood as infinite set of all existing objects and systems in the world, substrate of any properties, connections, relations and forms of motion which can be cognized on the basis of improvement of observation means and experiment.

During the process of isolating the education system from the real world through the set of views and ideas aiming at interpretation and explanation of this phenomenon it is presented as a natural integrity functioning within certain connections and directions of its internal motion (self-motion).

Tobias Roth and Manuel Siegert found out that education transitions are of a significant role to explain social inequality in education. One of the core factors for social and class transitions in critical point of the education system branching is the difference in education decisions of upper and lower social classes even at similar efficiency level. That is why institutional environment where families do not enjoy free choice, but where transitions are defined by mandatory teachers' recommendations based on the education performance is often supposed to be one of the opportunities to lessen social inequality having a chance to get education (Roth and Siegert, 2016).

Andrea G Forster и Herman $G$ van de Werfhorst singled out the role of parents' knowledge that corresponds to various sociological theories concerning inequality in education. Knowledge can influence the family's ability to make a rational choice in favour of education but it is a form of cultural capital as well. Parents' knowledge is a meaningful predicate of the educational success depending on their education, social and demographic profile and abilities being demonstrated (Forster and Werfhorst, 2020).

Michelle Jackson, Tatiana Khavenson $и$ Tatiana Chirkina are of the opinion that tests open the door to high level of social inequality in times of transition. In the mode of testing learners and their parents can focus all their energy and effort on the preparation for testing thus intensifying the inequality(Jackson, Khavenson and Chirkina, 2020).

Jane Beach $и$ Jane Bertrand Med suppose that the current implementation of early childhood development programmes are fragmentary. Education system is considered by many to be a better alternative to a more coherent approach having a necessary infrastructure in communities and it is well adapted to meet the requirements of all little children and their families. In Canada province and school authorities take on more early education programmes (Beach and Med, 2009).

F. Díez, A. Villa, A.L. López, I. Iraurgi found out an essential difference in the perception of a good school climate and the perception of high quality teaching. Management of an educational establishment is a significant factor. Although the behavior of teachers, learners and parents contributes to the school climate the attitude and activity of school principals and school boards are of a decisive character to maintain a favorable climate at school. Their conduct can either prevent from or contribute to the positive atmosphere. On the one hand, teachers rely on school principals concerning motivation, management and development. On the other hand, students depend on the leadership of schools to ensure high quality education (Díez, 
Villa, López and Iraurgi, 2020).

Kinya Tamaki, Masahiro Arakawa, Maki Arame и Yoshiyuki Ono single out two types of education programmes. The first programme presents the programme developer. It is capable of developing a new product design and innovative control using advanced technologies like loT (internet of things, i.e. physical object computing network objects («things»), equipped with embedded technologies to interact with each other or with external environment that considers such network formation as a phenomenon capable of reconstructing economic and social processes that exclude the necessity of human participation from a part of activities and operations), artificial intelligence, augmented and virtual reality. The second programme offers a business producer capable of business-modeling platform services, product and strategy development, customer service. Features of these programmes involve the application of new educational techniques combining project-based learning and active learning(Tamaki, Arakawa, Arame and Ono, 2019).

According to Ariane Basler and Irene Kriesi, formation of professional aspirations is an important challenge of teenage development and striving is a predicate of adult professionalism. The level and development of professional status aspirations of teenagers differ in the directions of higher secondary education. Over time BA students somewhat reduce their status aspiration, and those involved in some kinds of vocational education and vocational training significantly increase their striving (Basler and Kriesi, 2019).

Jeroen Huisman, Benedetto Lepori, Marco Seeber, Nicoline Frølich and Lisa Scordato showed that institutional variety of higher educational establishments within the framework of the higher education system is a popular problem of modern research (Huisman, Lepori, Seeber, Frølich and Scordato, 2015).

Humane maintenance of the country's economic security through the use of the education system within the UNESCO Programme on achievements of Sustainable Development Goals (SDGs) specified on the Agenda in sustainable development field for the period till 2030 adopted by the UNO General Assembly in 2015. UNESCO is a specialized agency of the United Nations on education, science and culture, it is striving for peace and security all over the world through international cooperation in these fields.

Since its foundation in 1945 UNESCO has been aimed at promoting peace, eradication of poverty, sustainable development and cross-cultural dialogue. UNESCO bears responsibility for the implementation of Sustainable Development Goal 4 i.e. to ensure inclusive and equitable quality education and promote lifelong learning opportunities for all based on the Framework Programme "Education 2030"

In the UNESCO Constitution Article 1 Purposes and Functions a global challenge is emphasized, i.e. to promote collaboration among the nations through education, science and culture in order to further universal respect for justice, for the rule of law and for the human rights and fundamental freedoms which are affirmed for the peoples of the world, without distinction of race, sex, language or religion (United Nations Educational Scientific and Cultural Organization, 2017).

Aiming at promoting international cooperation and ensuring continuity of the educational process amid the COVID-19 pandemic in March 2020 UNESCO launched the Global Education Coalition which is a multisectoral partnership among the UNO establishments, civil society bodies, Mass Media and IT partners to develop and implement innovation solutions. Jointly they help countries bridge content and coherence gaps as well as create opportunities for inclusive education of children and young people in the condition of a sudden and unprecedented disruption of the educational process.

Targets of UNESCO by 2030: (1) all girls and boys complete free, equitable and quality primary and secondary education leading to relevant and effective learning outcomes; (2) ensure equal access for all women and men to affordable and quality vocational and tertiary education including university; (3) increase the number of youth and adults who have relevant skills, including technical and vocational skills for employment, decent jobs and entrepreneurship; (4) eliminate gender disparities in education and ensure equal access to all levels of education and vocational training for the vulnerable, including persons with disabilities, indigenous peoples and children in vulnerable situations and etc.

\section{RESULTS}

Analysis of the Russian education system self-motion is conducted applying data of The World Bank Group which contain over 4000 international comparable indicators describing the access to education, training stages, literacy, teachers, societies and expenses. These indicators cover the education cycle from preschool to vocational and higher education. These data contain information on learning outcomes and forecast (achievement) data by 2050.

Neural network analysis growth rate of the Russian educational system resulted in hierarchy of significant 
indicators resembling the structure of the Russian educational system (Table 1). Feminization of the Russian educational system should be emphasized.

Table 1. Neural network analysis of the importance the rates of gain of indicators covering the cycle of education from preschool to vocational and higher education, 2000-2025.

\begin{tabular}{|c|c|}
\hline Indicator & $\begin{array}{l}\text { Inmorta } \\
\text { nce } \\
>60 \%\end{array}$ \\
\hline Primary education enrollment, female (number) & 100.0 \\
\hline $\begin{array}{l}\text { Ratio of gross enrollment in grade } 1 \text { of incomplete secondary general education, both } \\
\text { genders }(\%)\end{array}$ & 82.6 \\
\hline $\begin{array}{l}\text { Expenditure on education, unallocated by tier, as a percentage of government spending on } \\
\text { education }\end{array}$ & 74.6 \\
\hline Overall net enrollment rate, lower secondary education, both genders (\%) & 73.3 \\
\hline Share of learners in preschool education, female (\%) & 71.6 \\
\hline Cumulative dropout rate to the last grade of primary education, both genders (\%) & 70.0 \\
\hline Population, age 20 , total & 69.8 \\
\hline Grade 3 dropout rate of primary school, both genders (\%) & 68.7 \\
\hline Gross primary education enrollment rate, female (\%) & 68.1 \\
\hline Population, $11-15$ age group, female & 66.5 \\
\hline Enrollment in grade 1 of incomplete secondary education, female (number) & 65.8 \\
\hline Adjusted net enrollment rate for grade 1 of primary education, gender parity index & 64.2 \\
\hline Total number of university students going abroad, both genders (number) & 63.6 \\
\hline Average length of schooling, from primary to higher education, female (years) & 63.6 \\
\hline Gross enrollment rate, lower secondary education, male (\%) & 62.3 \\
\hline Население, возраст 6 лет, всего Population, age 6, total & 61.7 \\
\hline Higher education enrollment, all programmes, female, (number)) & 61.5 \\
\hline Net enrollment rate in primary education, gender parity index & 61.1 \\
\hline Population, $11-18$ age group, total & 60.8 \\
\hline Gross enrollment rate, higher education, male (\%) & 60.7 \\
\hline Population of official primary education age, male (number) & 60.5 \\
\hline Adjusted net enrollment rate for grade 1 of primary education, female (\%) & 60.4 \\
\hline
\end{tabular}

Note. Multilayer perceptron, batch training. 
Source: calculated in "IBM SPSS Statistics Software" according to the World Bank Group, All Rights Reserved. Data Catalog. https://datacatalog.worldbank.org (Access: 2020/09/07).

High priority educational positions are dominated by female gender: (1) primary education enrollment; (2) share of learners in preschool education; (3) gross primary education enrollment rate; (4) population 11-15 age group; (5) enrollment in grade 1 of incomplete secondary education; (6) average length of schooling, from primary to higher education; (7) higher education enrollment, all programmes; (8) adjusted net enrollment rate for grade 1 of primary education.

The male gender dominated in insignificant positions: (1) gross enrollment rate, lower secondary education; (2) gross enrollment rate, higher education; (3) population of official primary education age.

Comprehension of feminization of the Russian education system self-motion as a social phenomenon changing the principles of the society and family development, the system that specifies the dominant role of women, allows singling out it as a phenomenon of social reality having functional certainty in sucial and cultural sphere of the society.

Cluster analysis of the increase rate of the Russian education system self-motion resulted in singling out the priorities (Table 2): (1) the weightiest clusters are female gender, 2-3 age group; (2) composition ones are female gender 3-5 age group and male gender 4-5 age group.

Table 2. Weighty clusters the rates of gain social, economic, and demographic indicators covering the cycle of education from preschool to vocational and higher education, 2000-2025. The median the rates of gain social is greater than zero.

\begin{tabular}{|c|c|c|}
\hline & Weighty clusters (the square of the Eucli & an distance is less than one) \\
\hline 2.63E-03 & Population, age 3 y.o., total & Population age 3 y.o., female gender \\
\hline 3.81E-03 & Population, age 2 y.o., female gender & Population, age 2 y.o., total \\
\hline 5.89E-03 & Population, $3-5$ age group, total & Population, 3-5 age group, male gender \\
\hline 7.21E-03 & Population, age 4 y.o., female gender & Population, age 4 y.o., total \\
\hline $9.09 \mathrm{E}-03$ & Population, 4-6- age group, total & Population, 4-6 age group, male gender \\
\hline $1.08 \mathrm{E}-02$ & Population, age 5 y.o., female gender & Population, age 5 y.o.,total \\
\hline 1.17E-02 & $\begin{array}{l}\text { Population of legal preschool age, both } \\
\text { genders (number) }\end{array}$ & $\begin{array}{l}\text { Population of legal preschool age, male } \\
\text { gender (number) }\end{array}$ \\
\hline 1.57E-02 & Population, 3-5 age group, female gender & Population, $3-5$ age group, total \\
\hline 2.43E-02 & Population, 4-6 age group, female gender & Population, $4-6$ age group , total \\
\hline 3.08E-02 & $\begin{array}{l}\text { Population of legal preschool age, female } \\
\text { gender (number) }\end{array}$ & $\begin{array}{l}\text { Population of legal preschool age, both } \\
\text { genders (number) }\end{array}$ \\
\hline 8.41E-02 & $\begin{array}{l}\text { Average length of study, primary and lower } \\
\text { secondary school, male gender (years) }\end{array}$ & $\begin{array}{l}\text { Average length of study, primary and lower } \\
\text { secondary school, both genders(years) }\end{array}$ \\
\hline $1.15 \mathrm{E}-01$ & Population, age 24 y.o., total & Population, age 24 y.o., female gender \\
\hline $2.01 \mathrm{E}-01$ & Population, age 25 y.o., total & Population, age 25 y.o., female gender \\
\hline
\end{tabular}




\begin{tabular}{|l|l|l|}
\hline $\begin{array}{l}\text { the } \\
\text { square of } \\
\text { the } \\
\begin{array}{l}\text { Euclidean } \\
\text { distance }\end{array}\end{array}$ & \multicolumn{2}{|l|}{ Weighty clusters (the square of the Euclidean distance is less than one) } \\
\hline $2.22 \mathrm{E}-01$ & $\begin{array}{l}\text { Average length of study, primary and lower } \\
\text { secondary school, female gender (years) }\end{array}$ & $\begin{array}{l}\text { Average length of study, primary and lower } \\
\text { secondary school, male gender (years) }\end{array}$ \\
\hline $3.68 \mathrm{E}-01$ & Population, age 5 y.o., male gender & Population, 4-6 age group, female gender \\
\hline $5.57 \mathrm{E}-01$ & Population, 3-5 age group, female gender & Population, age 4 y.o., male gender \\
\hline $8.92 \mathrm{E}-01$ & Population, age 5 y.o., female gender & Population, age 5 y.o., male gender \\
\hline
\end{tabular}

Note: Hierarchical cluster analysis - the average distance between clusters, the square of the Euclidean distance.

Source: calculated in "IBM SPSS Statistics Software" according to the World Bank Group, All Rights Reserved. Data Catalog. https://datacatalog.worldbank.org (Access: 2020/09/07).

Consequently, inclination of internal motion of the Russian education system towards feminization is attributed to the early formation of the female cluster.

Thus, self-motion of the Russian education system is attributed to the dominance of women in the social reality. This phenomenon intensifies the uncertainty of the Russian society development influencing negatively the understanding of its existence prospects.

Analysis into the growth rate of the Russian education system self-motion applying data of The UNESCO Institute for Statistics allows us to accomplish the picture of education development prospects in Russia. It should be noted that UNESCO is an official and reliable source of international comparable data on education, science, culture and communication.

Being an official statistics body The UNESCO Institute for Statistics develops a wide range of modern data bases to support policy and investments necessary for transformation of life and promotion of the world towards its goals in the fields of education, science, culture and communication. The UNESCO Institute for Statistics has provided free access to the data on all countries and regional groups since 1970 and encourages developers and researchers to author web-sites and applications which widely use its data supports data browser and Bulk Data Download Service, BDDS.

Analysis into the growth rate of the Russian education system self-motion applying data of The UNESCO Institute for Statistics allows us to expose a negative phenomenon - a considerable decrease in the growth of preschool adolescents of younger middle age and preschool children of younger age. At the same time a positive dynamics is observed on reduction in the growth rate of the share of young children, children and adolescents who do not attend school. A significant lag in growth rate of government spending on education (\% of GDP) from spending on education as a percentage of total government spending causes perplexity as well. This fact shows other priority implementation for account of education.

Thus, analysis into the growth rate of the Russian education system self-motion on the data of The UNESCO Institute for Statistics resembles significant negative moments:(1) a significant decrease in preschool adolescents of younger middle age and preschool children of younger age; (2) a significant lag in the growth rate of government spending on education (\% of the GDP) against the spending on education as a percentage of the total government spending.

Analysis into the growth rate of the Russian education system self-motion applying data of The World Bank and the UNESCO Institute for Statistics exposes feminization as regards transformation of education changing principles of society and family development, and as a consequence, emphasizing female dominance. At the same time inclination of self-motion of the Russian education system towards feminization is attributed to the earlier formation of the female cluster.

David Kucera and Sheba Tejani point out that labor intensive textile and clothing industries were major drivers of female employment and technological modernization was associated with defeminization (Kucera 
and Tejani).

Rosa Aisa, Gemma Larramona and Fernando Pueyo having analyzed determinants of poverty among European workers on gender applying EU data (EC-SILC) in 25 countries showed that the risk of poverty is equal both for working men and women. This uniformity is superficial, since females are supposed to be in a relatively better position since they have a higher level of higher education, however, this advantage disappears when they enter the market. Most part-time jobs are held by females (Aisa, Larramona and Pueyo).

\section{CONCLUSIONS}

An increasing role of the education system in the new world technological structure taking shape stipulateds the urgency of its self-motion research (Smirnov, Zakharova, Talanova, Dulina, Gubanova and Getskina, 2019). The fact that the education system is a part of the social and economic formation intensifies this urgency.

The analysis of the Russian education system was conducted applying the data of the World Bank describing the access to the education, stages of study, literacy, teachers, societies, and expenses and those of the UNESCO Institute for Statistics applying its data base to support the policies and investments required for the life transformation and movement of the world towards its goals in the development of education, science, culture and communication. The analysis resulted in the exposure of the feminization observed in the Russian education system self-motion changing the principles of the society development, that intensifies the uncertainty of its existence prospects.

The following was revealed: a negative phenomenon of the Russian education system self-motion as a significant decrease in the growth rate of preschool adolescents of younger middle age and preschool children of younger age; a significant lag in the growth rate of government spending on education (\% of the GDP) against the spending on education as a percentage of the total government spending.

In the course of the discussion of the research results the following assertion was formulated. Self-motion of the Russian education system causes the education feminization, i.e. a risk of gender imbalance on the scientific and educational market in the world. This phenomenon results in a driving force of female employment in labour consuming textile and clothing industries. Technological modernization is connected with defeminization. Despite the fact that females have a high level of higher education this advantage disappears when they enter the market and get part-time jobs.

\section{REFERENCE LIST}

Adolfsson A., Ackerman M. and Brownstein N.C. (2019) To cluster, or not to cluster: An analysis of clusterability methods. Pattern Recognition, 88, 13-26. https://doi.org/10.1016/j.patcog.2018.10.026

Aisa R., Larramona G. and Pueyo F. (2019) Poverty in Europe by gender: The role of education and labour status. Economic Analysis and Policy, 63, 24-34. https://doi.org/10.1016/j.eap.2019.04.009

Ariane Basler, Irene Kriesi. Adolescents' development of occupational aspirations in a tracked and vocationoriented educational system. Journal of Vocational Behavior. 115, 103330. https://doi.org/10.1016/j.jvb.2019.103330

Beach J. and Med J.B. (2009) Early childhood programs and the education. Paediatrics \& Child Health, 14 (10), 666-668. https://doi.org/10.1093/pch/14.10.666

Brownstein N.C., Adolfsson A. and Ackerman M. (2019) Descriptive statistics and visualization of data from the $\mathrm{R}$ datasets package with implications for clusterability. Data in Brief, 25, Article 104004. https://doi.org/10.1016/j.dib.2019.104004

Díez F., Villa A., López A.L. and Iraurgi I. (2020) Impact of quality management systems in the performance of educational centers: educational policies and management processes. Heliyon. 6 (4), e03824. https://doi.org/10.1016/j.heliyon.2020.e03824

Favero L.P. and Belfiore P. (2019) Chapter 11: Cluster Analysis. Data Science for Business and Decision Making, 311-382. https://doi.org/10.1016/B978-0-12-811216-8.00011-2

Fávero L.P. and Belfiore P. (2019) Chapter 3: Univariate Descriptive Statistics. Data Science for Business 
and Decision Making, 21-91. https://doi.org/10.1016/B978-0-12-811216-8.00003-3

Federal Law of December 29, 2012 N 273-FZ (as amended on July 31, 2020). "On education in the Russian Federation" (as amended and supplemented, entered into force on 01.09.2020. Collected Legislation of the Russian Federation, 31.12.2012, N 53 (part 1), Art. 7598, Rossiyskaya Gazeta, N 303, 31.12.2012.http: //www.consultant.ru

Forster A.G. and Werfhorst H.G. (2020) Navigating Institutions: Parents' Knowledge of the Educational System and Students' Success in Education. European Sociological Review, 36 (1), 48-64. https://doi.org/10.1093/esr/jcz049

Huisman J., Lepori B., Seeber M., Frølich N. and Scordato L. (2015) Measuring institutional diversity across higher education systems. Research Evaluation, 24 (4), 369-379. https://doi.org/10.1093/reseval/rvv021

Jackson M., Khavenson T. and Chirkina T. (2020) Raising the Stakes: Inequality and Testing in the Russian Education System. Social Forces, 98 (4), 1613-1635. https://doi.org/10.1093/sf/soz113

King A.P. and Eckersley R.J. (2019) Chapter 1: Descriptive Statistics I: Univariate Statistics. Statistics for Biomedical Engineers and Scientists, 1-21. https://doi.org/10.1016/B978-0-08-102939-8.00010-4

Kucera D. and Tejani S. (2014) Feminization, Defeminization, and Structural Change in Manufacturing. World Development. 64, 569-582. https://doi.org/10.1016/j.worlddev.2014.06.033

Lazar J., Feng J.H. and Hochheiser H. (2019) Chapter 4: Statistical analysis. Research Methods in Human Computer Interaction (Second Edition), 71-104. https://doi.org/10.1016/B978-0-12-805390-4.00004-2

Roth T., and Siegert M. (2016) Does the Selectivity of an Educational System Affect Social Inequality in Educational Attainment? Empirical Findings for the Transition from Primary to Secondary Level in Germany. European Sociological Review, 32 (6), 779-791. https://doi.org/10.1093/esr/jcw034

Smirnov V.V., Semenov V.L., Zakharova A.N., Kadyshev E.N., Dulina G.S. (2019) Innovative management in Russian production companies. To cite this article: V V Smirnov et al 2019 IOP Conf. Ser.: Mater. Sci. Eng. 483 012060. doi:10.1088/1757-899X/483/1/012060.

Smirnov V.V., Talanova T.V., Zakharova A.N., Dulina G.S., Getskina I.B. and Huraskina N.V. (2018). Predictive Analysis Of The Russian Entrepreneurship Development. Proceedings of the International Business Information Management Association Conference (IBIMA). Vision 2020: Sustainable Economic Development and Application of Innovation Management from Regional expansion to Global Growth, 6949-6958.

Smirnov V.V., Zakharova A.N., Talanova T.V., Dulina G.S., Gubanova N.G., Getskina I.B. (2019) Entrepreneurship in the Russian Business Environment. Proceedings of the 33rd International Business Information Management Association Conference (IBIMA), 1806-1817.

Tamaki K., Arakawa M., Arame M. and Ono Y. (2019) Development of Educational Programs for System Creators and Business Producers in Future Strategy Design in Action Project Group Activities Through Industry-University Cooperation. Procedia Manufacturing, Volume 39, 2019, Pages 1377-1382. https://doi.org/10.1016/j.promfg.2020.01.319

United Nations Educational, Scientific and Cultural Organization. Basic documents. Charter of the United Nations Educational, Scientific and Cultural Organization. Adopted at London on 16 November 1945. Amended by the General Conference at the 2nd, 3rd, 4th, 5th, 6th, 7th, 8th, 9th, 10th, 12th, 15th, 17th 19th, 19th, 20th, 21st, 24th, 25th, 26th, 27th, 28th, 29th and 31st sessions. 2018 edition incorporating texts of documents and amendments adopted by the General Conference at its 39th session (Paris, 30 October - 14 November 2017). UNESCO Paris 201819 p.

Urlacher B.R. (2020) Complexity, Causality, and Control in Statistical Modeling. American Behavioral Scientist (ABS), 64 (1), 55-73. https://doi.org/10.1177/0002764219859641 